\title{
БЕЗБАРЬЕРНАЯ АРХИТЕКТУРНАЯ СРЕДА КАК ЭЛЕМЕНТ РЕАЛИЗАЦИИ ИНКЛЮЗИВНОГО ОБРАЗОВАНИЯ В ВУЗАХ Г. ТОМСКА
}

\author{
Носова Анастасия Леонидовна, \\ anastasiia.nosova@tusur.ru \\ Орлова Вера Вениаминовна, \\ orlova_vv@mail.ru \\ Томский государственный университет систем управления и радиоэлектроники, \\ Россия 634050, г. Томск, пр. Ленина, 40.
}

Носова Анастасия Леонидовна, ассистент кафедры управления инновациями Томского государственного университета систем управления и радиоэлектроники.

Орлова Вера Вениаминовна, доктор социологических наук, профессор кафедры философии и социологии Томского государственного университета систем управления и радиоэлектроники.

\begin{abstract}
Актуальность. Современная образовательная система Российской Федерации регулярно подвергается различного рода изменениям, которые в настоящее время ориентируются на политику открытости и доступности. С подписанием и ратификацией Конвенции ООН о правах инвалидов Россия взяла на себя обязательства по обеспечению социального участия людей с инвалидностью в жизни общества. В настоящее время стратегической целью государственной политики в области образования является его универсальность, доступность образовательного пространства для удовлетворения образовательных потребностей всех граждан страны. Цель работы - выявление актуального состояния инклюзивного образования в вузах города. Объектом исследования является безбарьерная архитектурная среда учебных корпусов вузов г. Томска для инвалидов с нарушениями опорно-двигательного аппарата, слуха и зрения ( $(n=17)$, а также студенческие группы, в которых обучаются студенты с инвалидностью и в которых таких студентов нет. Предметной сферой определены состояние, доступность и возможность освоения социального и физического пространства при получении высшего образования в инклюзивном формате. Основные методы исследования - социальная экспертиза, наблюдение на основе выделенных критериев оценки, методика «Синквейн», которая позволяет анализировать и объединять разные высказывания с учетом оценки контекста. В результате использование качественной стратегии позволило проанализировать условия, отражающие особенности безбарьерной среды в вузах.
\end{abstract}

Ключевые слова: Инклюзивное образование, безбарьерная среда, студенты с инвалидностью, принимающее, исключающее, нейтральное, противоречивое отношение.

В Концепции долгосрочного социально-экономического развития Российской Федерации до 2020 г. [1] в качестве целевых ориентиров, с одной стороны, выступает необходимость к 2020 г. охвата высшим и средним профессиональным образованием 60-70 \% населения страны, а с другой - разветвленной транспортной сети, обеспечивающей высокий уровень территориальной мобильности граждан.

Несмотря на достаточно большое количество предпринимаемых усилий и задействованных ресурсов актуальной задачей остается создание равных условий для лиц OB3 и инвалидностью. Развитие государственного потенциала априори включает в себя развитие образования. В свою очередь, стратегической целью государственной политики в области образования являются его универсальность, доступность образова- 
тельного пространства для удовлетворения образовательных потребностей всех граждан страны.

Образовательным организациям в современных условиях необходимо создавать среду, позволяющую успешное обучение каждого ученика, не допуская в отношении его дискриминации. Следовательно, всякая образовательная организация (среднего, среднего профессионального и высшего образования) должна быть доступной для каждого, включая лиц с особыми образовательными потребностями. Осуществление модели универсальности образовательного пространства для лиц с инвалидностью и ограниченными возможностями здоровья может реализовываться посредством инклюзивного или включенного образования.

Учитывая, что идея инклюзивного обучения достаточно нова для Российской Федерации, а взятые на себя международные обязательства (например, Европейская социальная хартия) предполагают высокие стандарты и требования, сложилась неблагоприятная ситуация с реализацией доступной среды в отечественном образовательном пространстве. На это нередко обращают внимание различные общественные объединения [2]. Ситуация реализации идей инклюзивного образования усугубляется особыми климатическими условиями на территории Российской Федерации, которые заметно тормозят распространение инклюзивной модели.

Исследуемая проблематика все чаще становится объектом внимания ученых. Вопросы, связанные с инклюзией в сфере образования, широко освещены в зарубежной и отечественной литературе.

Внимание ученых, исследующих проблемы инклюзии, привлекает сравнение зарубежного и отечественного опыта в формировании модели инклюзивного образования. В трудах Г. Зиммеля, П. Сорокина, Э. Дюркгейма делается акцент на элементах социального пространства, условиях и механизмах взаимодействия [3-5]. Такими авторами, как Ф.Л. Ратнер и Н.Г. Сигал [6] представлен аналитический обзор истории становления и развития идей инклюзивного образования детей с особыми образовательными потребностями в странах Европы и США, анализируется влияние социальнополитических явлений на этот процесс и опыт организации обучения детей с инвалидностью в общеобразовательных учреждениях за рубежом.

Подробный экскурс в историю становления модели инклюзивного образования проводит А. Тюрин [7]. В своей работе он рассматривает истоки специального образования, которое выступило в качестве пускового механизма для распространения идей инклюзии, также формирование сурдопедагогики и тифлопедагогики, становление дефектологии как науки, анализирует зарубежный и отечественный опыт в этих направлениях. Также исторические аспекты рассматриваются в работе В.В. Сизиковой и Н.А. Тюриной, которые анализируют зарубежный и российский опыт сопровождения студента-инвалида в условиях инклюзивного образования с целью выявления эффективных методов интеграции молодых инвалидов в образовательную среду $[8,9]$.

Вопросы перспектив развития инклюзивной модели в образовании описывает в своих работах Т.М. Ташина [10]. Автор проводит анализ будущего инклюзии в условиях Российской Федерации, которая подразумевает доступность образования для людей с инвалидностью и ограниченными возможностями, выделяет основные принципы и подходы, необходимые для успешной реализации инклюзивной модели в отечественных образовательных учреждениях.

Однако несмотря на объем накопленного теоретического опыта в области инклюзии и инклюзивного образования следует отметить, что исследователями комплексно не охарактеризованы особенности и компоненты инклюзивного образования в совре- 
менных реалиях, в частности аспекты, связанные с созданием безбарьерной архитектурной среды на базе высших учебных заведений, в связи с этим возникает потребность более подробного изучения данного аспекта.

Согласно нормативно-правовым основам, реализация модели инклюзивного образования должна осуществляться посредством организации доступной среды и исключения дискриминационного отношения к лицам, имеющим инвалидность и ограниченные возможности здоровья.

\section{Методы}

В рамках выявления отношения к лицам с инвалидностью и ОВ3 в вузовской среде было проведено анкетирование с использованием методики «Синквейн», которая позволяет анализировать и объединять разные высказывания с учетом оценки контекста (2018). В качестве объектов исследования выступили: студенческие группы, в которых обучаются студенты с инвалидностью и в которых таких студентов нет. В исследовании приняли участие студенты Национального исследовательского Томского государственного университета (НИ ТГУ) и Томского государственного университета систем управления и радиоэлектроники (ТУСУР). Всего было опрошено 100 респондентов из групп без студентов, имеющих инвалидность, и 134 респондента из студенческих групп, в которых обучаются студенты с инвалидностью и ограниченными возможностями здоровья. Среди студентов с инвалидностью двое имеют стойкие нарушения слуха, двое - нарушения опорно-двигательного аппарата, один - нарушения интеллектуального развития и четверо - соматические заболевания.

В рамках выявления актуального состояния инклюзивного образования в вузах г. Томска была проведена социальная экспертиза с целью анализа реализуемого состояния доступной среды в НИ ТГУ и ТУСУР. Исследование проводилось совместно со стажером Томского отделения Всероссийского общества инвалидов Т.В. Чуржаковой, которая имеет нарушения опорно-двигательного аппарата и передвигается на инвалидной коляске, и волонтером Центра доступности образования ТУСУР (ЦеДО) Р. Гибазовым, который выполнял функцию сопровождения.

Согласно нормативно-правовым основам организации инклюзивного образования в Российской Федерации в понятие доступной среды включаются безбарьерная среда для инвалидов всех нозологий, доступность официального сайта организации с учетом потребностей инвалидов по зрению, подготовка кадрового состава к работе с лицами, имеющими инвалидность и ограниченные возможности здоровья.

Для анализа организации безбарьерной среды в корпусах НИ ТГУ и ТУСУР были выделены основные критерии оценки доступности:

1) возможность беспрепятственного доступа к зданию (самостоятельно или нет);

2) наличие табличек, указывающих на вход, адаптированный для инвалида;

3) наличие пандусов;

4) наличие расширенных дверных проемов;

5) наличие гусеничного подъемника или лифта;

6) наличие специальных поручней на лестницах;

7) наличие специальной кнопки вызова персонала;

8) возможность беспрепятственного входа в объекты и выхода из них;

9) возможность самостоятельного передвижения по территории объекта в целях доступа к месту предоставления услуги;

10) содействие инвалиду при входе в объект и выходе из него;

11) содействие инвалиду на территории объекта; 
12) наличие при входе в объект вывески с названием организации, выполненной рельефно-точечным шрифтом Брайля и на контрастном фоне;

13) наличие при входе в объект графика работы организации, выполненного рельефно-точечным шрифтом Брайля;

14) наличие при входе на объект плана здания, выполненного рельефноточечным шрифтом Брайля или увеличенным шрифтом для слабовидящих;

15) наличие в одном из помещений индукционных петель и звукоусиливающей аппаратуры (наличие знака «безбарьерной среды для инвалида по слуху»);

16) наличие в здании оборудованной для инвалидов туалетной комнаты;

17) наличие внутри здания табличек и указателей, выполненных рельефноточечным шрифтом;

18) наличие специальной подготовки у персонала, непосредственно работающего с инвалидами (критерии преимущественно заимствованы из Письма Рособрнадзора [11] и Приказа Минобрнауки России «Об утверждении Порядка обеспечения условий доступности для инвалидов объектов и предоставляемых услуг в сфере образования, а также оказания им при этом необходимой помощи» [12], а частично выработаны автором самостоятельно).

Для проведения экспертизы были выбраны пять корпусов НИ ТГУ: главный (расположенный по адресу пр. Ленина, 36), спортивный (расположенный по адресу пр. Ленина, 36, к. 12), научная библиотека (расположенная по адресу пр. Ленина, 34a), второй (расположенный по адресу пр. Ленина, 36, к. 2) и четвертый (расположенный по адресу Московский тракт, 8). А также пять учебных корпусов ТУСУР: главный (расположенный по адресу пр. Ленина, 40), учебно-лабораторный (расположенный по адресу ул. Красноармейская, 146), радиотехнический (расположенный по адресу ул. Вершинина, 47), спортивный комплекс (расположенный по адресу Вершинина, 47, стр. 2), корпус факультета электронной техники (расположенный по адресу ул. Вершинина, 74).

Обследование корпусов проводилось 20 апреля 2019 года с 12.30 до 18.30 по местному времени.

\section{Описание результатов}

В ходе опроса респондентам предлагалось написать два прилагательных, три глагола, фразу из четырех слов и резюмирующее слово, ассоциирующиеся с темой «Студент с инвалидностью в группе». Полученные результаты были отнесены к одной из четырех категорий, указывающих на отношение студентов к лицам с инвалидностью: принимающее, исключающее, нейтральное и противоречивое отночение.

В целом полученные результаты анкетирования двух объектов являются в большей степени идентичными. Так, принимающеее отношение в группах совместно обучающихся с инвалидами продемонстрировало $43 \%$ респондентов, в группах же, где инвалиды не обучаются, - 50 \% респондентов.

Исключающую позицию среди студентов из групп совместно обучающихся с инвалидами заняли 19 \% опрошенных. В группах же, в которых инвалидов нет, эта цифра составляет $12 \%$. Противоречивую позицию по отношению к лицам с инвалидностью в обоих случаях заняли $11 \%$ респондентов.

Наибольшая разница наблюдается в категории «Нейтральное отношение». Так, 19 \% студентов, которые в реальности не обучаются совместно с инвалидами, занимают нейтральную позицию, в группах же, где имеются студенты-инвалиды, такой позиции придерживаются всего $5 \%$ опрошенных. В первую очередь это можно связать с тем, что в отличие от первой категории, которая только гипотетически проецирует си- 
туацию совместного обучения, представители второй группы уже сформировали свое отношение к инвалидам сознательно.

Таблица. Категории отношения студентов к инвалидам в рамках студенческого коллектива (из числа совместно обучающихся с инвалидами)

Table. Categories of student attitudes towards people with disabilities within the student body

(from the number of co-students with people with disabilities)

\begin{tabular}{|c|c|c|c|}
\hline $\begin{array}{c}\text { Тип высказыва- } \\
\text { ния/категория } \\
\text { Speech type/Category }\end{array}$ & $\begin{array}{c}\text { Абсолютная чистота, } \\
\text { чел. } \\
\text { Absolute cleanliness } \\
\text { (number of respondents) }\end{array}$ & $\begin{array}{l}\text { Относительная } \\
\text { чистота, \% } \\
\text { Relative purity } \\
\text { (percentage) } \\
\end{array}$ & $\begin{array}{c}\text { Характеризующие } \\
\text { слова/словосочетания } \\
\text { Characteristic words/phrases }\end{array}$ \\
\hline $\begin{array}{l}\text { Принимающее } \\
\text { отношение } \\
\text { Host attitude }\end{array}$ & 58 & 43 & \begin{tabular}{|l} 
«нормальный», «равный», «одинако- \\
вый», «упорный», «усердный», «це- \\
леустремленный», «веселый», «жиз- \\
нерадостный», «дружелюбный», \\
«помогать» и др. \\
«normal», «equal», «persistent», «zeal- \\
ous», «purposeful», «cheerful», «cheer- \\
ful», «friendly», «helping» and others
\end{tabular} \\
\hline $\begin{array}{l}\text { Исключающее } \\
\text { отношение } \\
\text { Exclusive attitude }\end{array}$ & 25 & 19 & $\begin{array}{l}\text { «ограниченный», «трудный», «про- } \\
\text { блемный», «никчемный», «беспо- } \\
\text { мощный», «жалкий», «слабый» и др. } \\
\text { «limited», «difficult», «problematic», } \\
\text { «worthless», «helpless», «miserable», } \\
\text { «weak» and others. }\end{array}$ \\
\hline $\begin{array}{l}\text { Нейтральное отношение } \\
\text { Neutral attitude }\end{array}$ & 7 & 5 & $\begin{array}{l}\text { «мне все равно», «не думал об этом», } \\
\text { «без разницы» и др. } \\
\text { «I don't care», «I didn't think about it», } \\
\text { «no difference» and others. }\end{array}$ \\
\hline $\begin{array}{l}\text { Противоречивые } \\
\text { высказывания } \\
\text { Conflicting statements }\end{array}$ & 15 & 11 & $\begin{array}{l}\text { упоминание одним респондентом } \\
\text { слов с положительной и отрицатель- } \\
\text { ной коннотацией } \\
\text { mention of positive and negative conno- } \\
\text { tations by one respondent }\end{array}$ \\
\hline $\begin{array}{l}\text { Незаполненные анкеты } \\
\text { Blank forms }\end{array}$ & 29 & 22 & - \\
\hline
\end{tabular}

Согласно результатам исследования двух объектов можно сделать вывод о том, что независимо от того, обучаются ли в группе инвалиды или нет, обе категории опрошенных чаще демонстрируют принимающее отношение к лицам с инвалидностью в группе. Следовательно, можно констатировать, что половина студентов, в группах, где лица с инвалидностью отсутствуют, гипотетически придерживаются принимающей позиции. Точно также большинство респондентов из групп, в которых такие студенты учатся, фактически принимают их в свой коллектив. Также фактическое наличие студентов с инвалидностью в группе обуславливают разницу в количестве респондентов, демонстрирующих исключающее отношение к инвалидам. Другими словами, респонденты, которые только представляют совместное обучение с инвалидами, могут занимать принимающую или нейтральную позицию, но при реальном взаимодействии их мнение может измениться в любую из сторон.

Таким образом, согласно результатам анкетирования, выявлено, что вопреки бытующему мнению об исключении инвалидов из социума в связи с непринятием общества их особенностей, большинство респондентов, независимо от того, фактически ли 
они взаимодействуют с инвалидами или гипотетически проецируют данную ситуацию, высказывают принимающее отношения к лицам с инвалидностью в вузовской среде.

1. В процессе экспертной оценки было выявлено, что 1/2 объектов не предназначены для пользования инвалидами всех нозологий. Так, к четвертому корпусу НИ ТГУ, радиотехническому и спортивному корпусам ТУСУР отсутствует даже возможность беспрепятственного доступа для инвалида-колясочника.

2. Для того чтобы добраться до четвертого корпуса ТГУ, есть всего три возможных варианта, два из которых не предназначены для лиц с нарушениями опорнодвигательного аппарата, передвигающихся на кресле-коляске, и один является «пригодным» в случае использования совместно с сопровождающим. Инвалиду приходится использовать его для того, чтобы спуститься к корпусу. Спуск расположен на проезжей части с интенсивным дорожным движением. Самостоятельно проехать по спуску инвалид-колясочник не в силах, поэтому он вынужден просить посторонней помощи.

3. Кроме того, для того, чтобы подъехать вплотную к корпусу, инвалиду необходимо преодолеть несколько бордюр и дорожных ям, которые также без посторонней помощи проехать проблемно. Помимо этого, попасть непосредственно в здание четвертого корпуса ТГУ инвалиду-колясочнику невозможно. Возле корпуса отсутствует кнопка вызова персонала, который мог бы предоставить помощь инвалиду при входе в объект, а самостоятельно преодолеть высокую лестницу инвалид-колясочник не в состоянии. Также в корпусе отсутствует гусеничный подъемник и лифт, пандусы, оборудованная туалетная комната, а из специальных поручней имеется только один, расположенный слева от главной лестницы при входе в здание.

Наблюдение: во время проведения исследования, опираясь на указанный поручень, поднималась девушка с ДЦП, предположительно - студентка ТГУ. Поручень закончился раньше, чем сама лестница, и девушке приходилось придерживаться стены, для того чтобы попасть внутрь здания. Помимо отсутствия условий для инвалидов с нарушениями опорно-двигательного аппарата, в корпусе также не предусмотрены условия для инвалидов, имеющих нарушения зрения и слуха (отсутствуют специальные таблички, выполненные рельефно-точечным шрифтом Брайля и аудитория с индукционной петлей). Иными словами, четвертый корпус ТГУ не является приспособленным для обучения инвалидов.

4. Внеучебное пространство также должно соответствовать доступности (наличие средств навигационной поддержки) [13]. В процессе обследования учебных корпусов НИ ТГУ была проведена оценка доступности научной библиотеки ТГУ, которую посещают студенты и сотрудники разных вузов города. Было установлено, что без посторонней помощи попасть внутрь объекта инвалиду-колясочнику не представляется возможным (при входе расположена высокая лестница, пандус отсутствует). При этом возле лестницы расположена специальная кнопка вызова персонала. После нажатия указанной кнопки инвалидом, специалист библиотеки спустился к нему в течение трех минут. Однако помощи от специалиста не последовало, т. к. «сопроводители инвалидов работают только в будние дни, а в субботу такой персонал отсутствует», как пояснил специалист библиотеки.

5. Главный корпус НИ ТГУ оборудован лишь для инвалидов с нарушением опорно-двигательного аппарата. Внутри корпуса отсутствуют условия, удовлетворяющие потребности инвалидов с нарушениями слуха и зрения. При этом следует заметить, что инвалидам, имеющим нарушения опорно-двигательного аппарата самостоятельно попасть в корпус и передвигаться внутри него невозможно. Для того чтобы попасть внутрь объекта, инвалиду-колясочнику необходимо воспользоваться кнопкой вызова 
персонала. В день экспертизы персонал организации никак не среагировал на вызов по кнопке, которую эксперт нажимала несколько раз с периодичностью в 3-5 минут. После этого сопровождающий волонтер самостоятельно решил обратиться к сотрудникам вахты. При обращении на вахту выяснилось, что сотрудники приняли сигнал вызова за сбой в системе и выключили аппаратуру. По просьбе сопровождающего волонтера к эксперту спустился сотрудник охраны с гусеничным подъемником, который обычно работает непосредственно с инвалидами, обучающимися в главном корпусе ТГУ и оказывает им помощь при входе и выходе на объект, а также при перемещении по этажам объекта, и, при необходимости, сопровождает их в туалетную комнату.

6. Проблемные ситуации также возникли и при обследовании второго корпуса НИ ТГУ. Важно заметить, что при входе в корпус имеется пандус, по которому инвалид может самостоятельно подъехать к двери, но без посторонней помощи открыть эту дверь инвалиду проблематично. В связи с этим возле нее расположена кнопка вызова персонала, который, по «задумке администрации», в случае необходимости должен выйти и помочь инвалиду открыть дверь. К сожалению попытки воспользоваться помощью кнопкой не привели к успеху.

7. Внутри корпуса беспрепятственно инвалид может перемещаться только по левому крылу первого этажа, т. к. с этой стороны расположен пандус. Гусеничного подъемника в здании нет, следовательно, попасть на другие этажи корпуса возможности не представляется. В связи с этим в левом крыле первого этажа должна быть расположена специально оборудованная туалетная комната для инвалидов, с обнаружением которой возникли трудности. После уточнения у сотрудницы вахты о расположении туалета, выяснилось, что в крайнем углу мужского туалета имеется отдельная оборудованная кабинка для инвалидов и для того чтобы до нее добраться, девушке-инвалиду необходимо проехать через общую туалетную комнату, в которой могут находиться мужчины в открытых кабинках без дверей. Также при передвижении внутри корпуса Татьяне на кресле-коляске 2 раза не достаточно было ширины в дверных проемах, расположенных в коридоре, а выбираться из них инвалиду помогал сопровождающий волонтер. Сотрудники учреждения своей помощи не предложили. Из этого можно сделать вывод о том, что персонал, в частности сотрудница вахты, работающий во втором корпусе ТГУ является недостаточно квалифицированным, не имеет специальных знаний в вопросах работы с лицами, имеющими инвалидность и ограниченные возможности здоровья. Кроме того, так же как предыдущий корпус, данный корпус не оборудован с учетом нужд инвалидов с нарушениями слуха и зрения.

Согласно Методическим рекомендациям по организации образовательного процесса для обучения инвалидов и лиц с ограниченными возможностями здоровья в образовательных организациях высшего образования, утвержденными Минобрнауки РФ [14], во всех вузах Российской Федерации для инвалидов очной формы обучения рекомендуется разрабатывать индивидуальные программы по адаптивной физической культуре, которая осуществляется на базе спортивных корпусов университета. Следовательно, инвалид с любой нозологией должен иметь возможность беспрепятственно попадать в спортивный корпус для прохождения занятий. При этом попасть в спортивные корпуса НИ ТГУ и ТУСУР инвалиду-колясочнику невозможно.

8. При входе в спортивный корпус НИ ТГУ расположена высокая лестнища, без поручней и пандусов. Кнопка вызова персонала, который мог бы оказать помощь инвалиду при входе в объект и передвижению внутри него, отсутствует. Внутри объекта доступная среда не соответствует требованиям: отсутствуют оборудованная для инвалидов туалетная комната, таблички, выполненные рельефно-точечным шрифтом Брайля, указа- 
тели и пр. Единственным реализуемым критерием является то, что до самого корпуса инвалид-колясочник может добраться самостоятельно, без посторонней помощи. Беспрепятственно же добраться до спортивного комплекса ТУСУР не удалось. Путь к корпусу требует также технически-коммунального ухода, т. к. для колес инвалидного кресла движение затруднено. При этом следует отметить, что вблизи главной лестницы расположен устаревший требующий ремонта пандус, которым невозможно воспользоваться.

9. При подъезде к зданию радиотехнического корпуса ТУСУР встречается трехступенчатая лестница, высокие бордюры и ямы. Кроме этого, в связи с таяньем снега на протяжении маршрута до корпуса встречались лужи, которые сложно было объехать. Возле основного и единственного входа в здание очередным препятствием для инвалида-колясочника стала лестница, подняться по которой самостоятельно невозможно. Кнопка вызова персонала также отсутствовала, а для того чтобы попасть внутрь здания, инвалидам предлагается позвонить по специальному номеру, указанному на табличке у входа. Предполагалось, что, позвонив по указанному номеру, инвалид должен был связаться с ответственным сотрудником вахты, который оказывает помощь при входе в здание и передвижении внутри него. Набрав указанный телефонный номер дважды, ответа от сотрудников вахты не последовало. Согласно вышеизложенному, можно сделать вывод о том, что табличка при входе, указывающая на условную доступность объекта для лиц с ограниченными возможностями является фиктивной и в реальности обеспечение доступной среды не осуществляется.

Подобная ситуация ожидала инвалида-колясочника и при входе в корпус факультета электронной техники ТУСУР. Как и в предыдущем случае, у входа расположена табличка с номером сотрудника вахты сопровождающего инвалидов. Дозвониться по указанному номеру не удалось, а после беседы с сотрудницей вахты выяснилось, что табличка, обозначающая условную доступность объекта для инвалидов, висит «для отчетности». Инвалиды на данный момент в корпусе не обучаются, а даже если бы они были, то их сопровождение, со слов сотрудницы, «должны осуществлять родственники, а никак не работники вуза».

10. При обследовании главного корпуса ТУСУР также возникли трудности при входе в объект. Самостоятельно инвалиду-колясочнику попасть в корпус через парадную дверь затруднительно. Для того чтобы попасть внутрь здания, инвалиду можно воспользоваться звонком (предположительно - кнопка вызова персонала), расположенным возле основного входа. При этом кнопка выглядит как обычный дверной звонок и расположена на расстоянии около 1,5 метров от земли. Иными словами, инвалидколясочник самостоятельно до нее дотянуться не может. Помимо кнопки, на двери расположена табличка с номером телефона сопровождающего сотрудника. Позвонив на указанный номер, к эксперту вышла сотрудница вахты, которая пояснила, что в будние дни инвалид может беспрепятственно попасть в корпус через задний двор, там же расположена дополнительная кнопка вызова персонала, проезд к которому закрыт в субботу и воскресенье.

Следует заметить, что о входе для инвалидов с обратной стороны здания можно узнать только со слов сотрудников, специальные указатели, обозначающие этот оборудованный вход, отсутствуют. А для того чтобы попасть внутрь через парадную дверь, инвалиду-колясочнику необходима помощь как минимум трех человек, двое из которых должны держать двери, а последний - перевозить кресло-коляску через порог.

Далее, будучи непосредственно в корпусе, инвалид-колясочник беспрепятственно может передвигаться только в пределах первого этажа, гусеничного подъемника в здании нет, в связи с этим попасть на другие этажи корпуса на кресле-коляске невозмож- 
но. Комфортное пребывание студентов с нарушениями опорно-двигательного аппарата в учебных и других корпусах возможно при условии наличия специализированных помещений [15-17]. Так, на первом этаже расположена оборудованная для инвалидов туалетная комната, вблизи нее находится аудитория, оборудованная индукционной петлей и имеющая специальный компьютер, оснащенный программой для лиц, имеющих нарушения зрения. Тем не менее рельефно-точечных указателей, выполненных шрифтом Брайля, и указателей, обозначающих доступную среду для инвалидов с нарушением слуха, т. е. наличие в аудитории индукционной петли, нет $[18,19]$.

Таким образом, главный корпус ТУСУР является частично доступнылм для инвалидов с нарушениями опорно-двигательного аппарата и нарушениями слуха. Полноценная безбарьерная архитектурная среда инвалидов всех нозологий на объекте отсутствует [20,21].

11. Единственный из обследуемых корпусов, в который беспрепятственно и самостоятельно может попасть инвалид-колясочник, а также передвигаться по всем этажам без посторонней помощи является учебно-лабораторный корпус ТУСУР. В здании выделен отдельный вход для инвалидов, который оборудован кнопкой вызова персонала, удобным пандусом, специальным ковриком для слепых и слабовидящих, вывеской с названием организации, выполненной рельефно-точечным шрифтом Брайля с графиком ее работы. При входе в объект имеется также план здания, выполненный рельефноточечным шрифтом Брайля. Внутри корпуса имеется специально оборудованный, с учетом потребностей лиц с инвалидностью, лифт. На первом этаже расположены специальные туалетные комнаты (отдельно мужская и женская) для инвалидов, главная лестница оборудована специальными поручнями, на стенах имеются указатели для слепых и слабовидящих, обозначающие движение. Кроме того, сотрудники вахты, при встрече с инвалидом, предлагают ему свою помощь и дальнейшее сопровождение внутри объекта. Но, несмотря на организацию безбарьерной среды для лиц с нарушениями зрения и опорно-двигательного аппарата, в корпусе отсутствует специально оборудованная аудитория с учетом потребностей слабослышащих.

\section{Выводы}

1. В результате проведенной оценки доступности учебных корпусов НИ ТГУ и ТУСУР, можно сделать вывод о том, что большая часть обследуемых объектов не приспособлены для инвалидов всех нозологий.

2. Только один (главный корпус ТУСУР) из 10 обследованных корпусов двух вузов города соответствует требованиям и предназначен для инвалидов с нарушениями слуха, еще один (учебно-лабораторный корпус ТУСУР) отвечает большей части требований по организации доступной среды для инвалидов с нарушениями зрения.

3. Для инвалидов с нарушениями опорно-двигательного аппарата полностью приспособлен учебно-лабораторный корпус ТУСУР, частично отвечают потребностям данной категории главный корпус ТГУ, второй корпус ТГУ и главный корпус ТУСУР.

4. Уровень организации безбарьерной для инвалидов среды и, следовательно, реализации модели инклюзивного образования в Томском государственном университете и Томском государственном университете систем управления и радиоэлектроники требует дальнейшего совершенствования.

5. Кроме безбарьерных архитектурных условий в организацию полноценной доступной среды входит адаптированность официального сайта организации с учетом потребностей лиц с инвалидностью и ограниченными возможностями здоровья, а также размещение на сайте информации, необходимой для данных категорий граждан. 


\section{СПИСОК ЛИТЕРАТУРЫ}

1. Концепция долгосрочного социально-экономического развития Российской Федерации на период до 2020 года // Правительство России. URL: http://government.ru/info/6217/ (дата обращения 15.04.2020).

2. Европейская Социальная Хартия ETS N 163 // Информационно-правовой портал Гарант.py. URL: http://base.garant.ru/2541037/\#ixzz4TuiJLYSV (дата обращения 16.12.2019).

3. Дюркгейм Э. Социология. Её предмет, метод, предназначение. - М.: Канон, 1995. - 350 с.

4. Зиммель Г. Социальная дифференциация. Социологические и психологические исследования // Избранное. Т. 2. Созерцание жизни. - М.: Юрист, 1996. - С. 301-345.

5. Сорокин П. Человек. Цивилизация. Общество. - М.: Политиздат, 1992. - 543 с.

6. Филиппов А.Ф. Теоретические основания социологии пространства. - М.: Канон-Пресс-Ц, 2003. - 230 с.

7. Ратнер Ф.Л., Сигал Н.Г. История становления и развития идей инклюзивного образования: международный опыт // Исторические, философские, политические и юридические науки, культурология, искусствоведение. Вопросы теории и практики. - 2012. - № 12. - Ч. 2. - С. 162-167. URL: https://www.gramota.net/materials/3/2012/12-2/38.html (дата обращения 16.12.2019).

8. Тюрин А. История появления и развития инклюзивного образования // Точки над Ё. $-2015 .-$ № $1 .-$ C. 95-134.

9. Клоков В.В. К дискурсу о понятии инвалидности: неограниченные возможности в ограниченном обществе // Социальные технологии, исследования. - 2011. - № 1. - С. 24-37.

10. Сизикова В.В., Тюрина Н.А. Зарубежный и российский опыт сопровождения молодого инвалида в условиях инклюзивного образования // Социальная политика и социология. - 2012. - № 3 (81). - С. 7-17.

11. О направлении методических рекомендаций для экспертов, участвующих в мероприятиях по государственному контролю (надзору), лицензионному контролю по вопросам организации инклюзивного образования и создания специальных условий для получения среднего профессионального образования инвалидами и лицами с ограниченными возможностями здоровья: письмо Рособрнадзора от 14.11.2016 № 05-616. URL: https://legalacts.ru/doc/pismo-rosobrnadzora-ot-14112016-n-05-616-onapravlenii-metodicheskikh/ (дата обращения 15.04.2020).

12. Об утверждении Порядка обеспечения условий доступности для инвалидов объектов и предоставляемых услуг в сфере образования, а также оказания им при этом необходимой помощи: приказ Мин-обрнауки России от 09.11.2015 № 1309 (ред. от 18.08.2016). URL: http://base.garant.ru/71275174/ (дата обращения 15.04.2020).

13. Ташина Т.М. Инклюзивное образование в дошкольном учебном учреждении // Учёные записки СПбГИПиСР. - 2013. - № 2. - С. 86-90.

14. Методические рекомендации по организации образовательного процесса для обучения инвалидов и лиц с ограниченными возможностями здоровья в образовательных организациях высшего образования, в том числе оснащенности образовательного процесса (утв. зам. Министра МОиН РФ А.А. Климовым 08.04.2014 № AK-44/05вн) // Гарант.py. URL: http://base.garant.ru/70680520/ (дата обращения 31.03.2018).

15. Зинкевич О.В., Дегтярева В.В., Дегтярева Т.Н. Инклюзивное образование в Российской высшей школе: современные вызовы // Власть. - 2016. - № 5. - С. 61-66.

16. Коржук С.В. Социальная эксклюзия людей с инвалидностью: успешные стратегии преодоления // Мир экономики и управления. - 2016. - Т. 16. - № 2. - С. 145-155.

17. Мартынова Е.А., Романенкова Д.Ф. Требования к специальным условиям обеспечения инклюзивного образования инвалидов в организациях профессионального образования // Историческая и социально-образовательная мысль. - 2013. - № 4. - С. 98-102. URL: https://elibrary.ru/item.asp?id=20362671 (дата обращения 15.04.2020).

18. Bonela Ganapathi. Does inclusive higher education can help for physical disability handicapped people in India? A comparative analysis // International Journal of Research in Applied, Natural and Social Sciences 2014. - V. 2. - № 5. - C. 1-16.

19. Петросян В.А. Интеграция инвалидов в российское общество: автореф. дис. ... канд. соц. наук. - М., 2011. -42 c.

20. Ситнова И.В. Активистско-деятельностная методология в моделировании процесса «институциональных изменений» // Экономика и социум: современные модели развития. - 2011. - № 1. - С. 64-70.

21. Нестерова А.А. Функционалистский подход к совместному образованию и социальной адаптации детей с ограниченными возможностями здоровья и детей, не имеющих нарушений развития // Социальная политика и социология. - 2012. - № 3. - С. 85-90.

Поступила 14.06.2020 г. 


\title{
BARRIER-FREE ARCHITECTURAL ENVIRONMENT AS AN ELEMENT OF INCLUSIVE EDUCATION IN TOMSK UNIVERSITIES
}

\author{
Anastasia L. Nosova, \\ anastasiia.nosova@tusur.ru \\ Vera V. Orlova, \\ orlova_vv@mail.ru
}

Tomsk State University of Control Systems and Radioelectronics, 40, Lenin avenue, Tomsk, 634050, Russia.

\begin{abstract}
Anastasia L. Nosova, assistant, Tomsk State University of Control Systems and Radioelectronics.
Vera V. Orlova, Dr. Sc., professor, Tomsk State University of Control Systems and Radioelectronics

Relevance. The modern educational system of the Russian Federation is regularly subjected to various kinds of changes, which, at present, are oriented towards a policy of openness and accessibility. With the signing and ratification of the UN Convention on the Rights of Persons with Disabilities, Russia has committed itself to ensuring the social participation of people with disabilities in society. At present, the strategic goal of state policy in the field of education is its universality, the availability of educational space to meet the educational needs of all citizens of the country. The purpose of the work is to identify the current status of inclusive education in the universities of the city. The object of the study is the barrier-free architectural environment of the educational buildings of Tomsk universities for the disabled with impaired musculoskeletal system and for the disabled with hearing impairment (n=17), as well as student groups in which students with disabilities are studying, and student groups in which there are no such students. The subject area defines the state, accessibility and the possibility of mastering the social and physical space when obtaining higher education in an inclusive format. The main research methods are social examination, observation based on the selected evaluation criteria, the «Sinkwine» methodology, which allows you to analyze and combine different statements taking into account the assessment of the context. As a result, the use of a quality strategy made it possible to analyze conditions that reflect the characteristics of the barrier-free environment in universities.
\end{abstract}

Key words: Inclusive education, barrier-free environment, students with disabilities, accepting, excluding, neutral, contradictory attitude.

\section{REFERENCES}

1. Kontseptsiya dolgosrochnogo sotsialno-ekonomicheskogo razvitiya Rossiyskoy Federatsii na period do 2020 goda [The concept of long-term socio-economic development of the Russian Federation for the period up to 2020]. Pravitelstvo Rossii. Available at: http://government.ru/info/6217/ (accessed 15 April 2020).

2. Evropeyskaya Sotsialnaya Khartiya ETS N 163 [European Social Charter ETS N 163]. Garant.ru. Available at: http://base.garant.ru/2541037/\#ixzz4TuiJLYSV (accessed 16 December 2019).

3. Dyurkgeym E. Sotsiologiya. Ee predmet, metod, prednaznachenie [Sociology. Its subject, method, purpose]. Moscow, Kanon Publ., 1995. 350 p.

4. Zimmel G. Sotsialnaya differentsiatsiya. Sotsiologicheskie i psikhologicheskie issledovaniya [Social differentiation. Sociological and Psychological Research]. Izbrannoye. T. 2. Sozertsaniye zhizni. Moscow, Yurist Publ., 1996. pp. 301-345.

5. Sorokin P. Chelovek. Tsivilizatsiya. Obshchestvo [Man. Civilization. Society]. Moscow, Politizdat Publ., 1992. 543 p.

6. Filippov A.F. Teoreticheskie osnovaniya sotsiologii prostranstva [Theoretical foundations of the sociology of space]. Moscow, Kanon-Press-TS Publ., 2003. 230 p.

7. Ratner F.L., Sigal N.G. Istoriya stanovleniya i razvitiya idey inklyuzivnogo obrazovaniya: mezhdunarodny opyt [History of the formation and development of the ideas of inclusive education: international experience]. Istoricheskie, filosofskie, politicheskie i yuridicheskie nauki, kulturologiya, iskusstvovedenie. Voprosy teorii i 
praktiki, 2012, no. 12, P. 2, pp. 162-167. Available at: https://www.gramota.net/materials/3/2012/122/38.html (accessed 16 December 2019).

8. Tyurin A. Istoriya poyavleniya i razvitiya inklyuzivnogo obrazovaniya [History of the emergence and development of inclusive education]. Tochki nad $\ddot{E}$, 2015, no. 1, pp. 95-134.

9. Klokov V.V. K diskursu o ponyatii invalidnosti: neogranichennye vozmozhnosti $v$ ogranichennom obshchestve [Towards a discourse on the concept of disability: unlimited opportunities in a limited society]. Sotsialnye tekhnologii, issledovaniya, 2011, no. 1, pp. 24-37.

10. Sizikova V.V., Tyurina N.A. Zarubezhny i rossiyskiy opyt soprovozhdeniya molodogo invalida v usloviyakh inklyuzivnogo obrazovaniya [Foreign and Russian experience of accompanying a young disabled person in the conditions of inclusive education]. Sotsialnaya politika $i$ sotsiologiya, 2012, no. 3 (81), pp. 7-17.

11. O napravlenii metodicheskikh rekomendatsiy dlya ekspertov, uchastvuyushchikh $v$ meropriyatiyakh po gosudarstvennomu kontrolyu (nadzoru), litsenzionnomu kontrolyu po voprosam organizatsii inklyuzivnogo obrazovaniya $i$ sozdaniya spetsialnykh usloviy dlya polucheniya srednego professionalnogo obrazovaniya invalidami i litsami s ogranichennymi vozmozhnostyami zdorovya [On the direction of methodological recommendations for experts participating in measures for state control (supervision), licensing control on the organization of inclusive education and the creation of special conditions for obtaining secondary vocational education for disabled people and persons with disabilities]. Pismo Rosobrnadzora ot 14.11.2016 N 05-616 [Rosobrnadzor letter of 11.14.2016 N 05-616]. Available at: https://legalacts.ru/doc/pismo-rosobrnadzora-ot14112016-n-05-616-o-napravlenii-metodicheskikh/ (accessed 15 April 2020).

12. Ob utverzhdenii Poryadka obespecheniya usloviy dostupnosti dlya invalidov obektov i predostavlyaemykh uslug $v$ sfere obrazovaniya, a takzhe okazaniya im pri etom neobkhodimoy pomoshchi [On approval of the Procedure for ensuring the conditions for accessibility of facilities and services provided in the field of education for disabled people, as well as providing them with the necessary assistance]. Prikaz Minobrnauki Rossii ot 09.11.2015 N 1309 (red. ot 18.08.2016). [Order of the Ministry of Education and Science of Russia dated 09.11.2015 N 1309 (as amended on 18.08.2016)]. Available at: http://base.garant.ru/71275174/ (accessed 15 April 2020).

13. Tashina T.M. Inklyuzivnoe obrazovanie $\mathrm{v}$ doshkolnom uchebnom uchrezhdenii [Inclusive education in a preschool educational institution]. Uchenye zapiski SPbGIPiSR, 2013, no. 2, pp. 86-90.

14. Metodicheskie rekomendatsii po organizatsii obrazovatelnogo protsessa dlya obucheniya invalidov i lits $\mathrm{s}$ ogranichennymi vozmozhnostyami zdorovya $\mathrm{v}$ obrazovatelnykh organizatsiyakh vysshego obrazovaniya, $\mathrm{v}$ tom chisle osnashchennosti obrazovatelnogo protsessa (utv. zam. Ministra MOiN RF A.A. Klimovym 08.04.2014 № AK-44/05vn) [Methodical recommendations on the organization of the educational process for teaching disabled people and persons with disabilities in educational institutions of higher education, including the equipment of the educational process (approved by the Deputy Minister of the Ministry of Education and Science of the Russian Federation A.A. Klimov 08.04.2014 No. AK-44 / 05vn]. Garant.ru. Available at: http://base.garant.ru/70680520/ (accessed 31 March 2018).

15. Zinkevich O.V., Degtyareva V.V., Degtyareva T.N. Inklyuzivnoe obrazovanie v Rossiyskoy vysshey shkole: sovremennye vyzovy [Inclusive education in Russian higher school: modern challenges]. Vlast, 2016, no. 5, pp. 6166.

16. Korzhuk S.V. Sotsialnaya eksklyuziya lyudey s invalidnostyu: uspeshnye strategii preodoleniya [Social exclusion of people with disabilities: successful coping strategies]. Mir ekonomiki i upravleniya, 2016, vol. 16, no. 2 , pp. $145-155$.

17. Martynova E.A., Romanenkova D.F. Trebovaniya k spetsialnym usloviyam obespecheniya inklyuzivnogo obrazovaniya invalidov v organizatsiyakh professionalnogo obrazovaniya [Requirements for special conditions for ensuring inclusive education of disabled people in vocational education organizations]. Istoricheskaya $i$ sotsialno-obrazovatelnaya mysl, 2013, no. 4, pp. 98-102. Available at: https://elibrary.ru/item.asp?id=20362671 (accessed 15 April 2020).

18. Bonela Ganapathi. Does inclusive higher education can help for physical disability handicapped people in India? A comparative analysis. International Journal of Research in Applied, Natural and Social Sciences, 2014, vol. 2, no. 5, pp. 1-16.

19. Petrosyan V.A. Integratsiya invalidov v rossiyskoe obshchestvo. Avtoreferat Dis. Kand. nauk [Integration of disabled people into Russian society: Cand. Diss. Abstract]. Moscow, 2011. 42 p.

20. Sitnova I.V. Aktivistsko-deyatelnostnaya metodologiya V modelirovanii protsessa «institutsionalnykh izmeneniy» [Activist-activity methodology in modeling the process of «institutional changes»]. Ekonomika $i$ sotsium: sovremennye modeli razvitiya, 2011, no. 1, pp. 64-70.

21. Nesterova A.A. Funktsionalistskiy podkhod k sovmestnomu obrazovaniyu i sotsialnoy adaptatsii detey $\mathrm{s}$ ogranichennymi vozmozhnostyami zdorovya i detey, ne imeyushchikh narusheniy razvitiya [Functionalist approach to joint education and social adaptation of children with disabilities and children without developmental disabilities]. Sotsialnaya politika i sotsiologiya, 2012, no. 3, pp. 85-90.

Received: 14 June 2020. 